interventions that are not cost-effective.

\section{Tarique Khan,}

29 Grantham Road, Sparkbrook,

Birmingham, B11 $1 \mathrm{LU}$.

E-mail: drtariq.khan@doctors.org.uk

\section{Amanda Beaumont,}

NHS Walsall, Jubilee House, Bloxwixh Lane, Walsall, WS2 7JL.

\section{REFERENCES}

1. Department of Health. A simple guide to MRSA 2007 http://www.dh.gov.uk/prod_consum_dh/groups/dh digitalassets/@dh/@en/documents/digitalasset/dh_07 6839.pdf (accessed 11 Jun 2010).

2. Biedendach D, Moet G, Jones R. Occurrence and antimicrobial resistance pattern comparisons among bloodstream infection isolates from the SENTRY Antimicrobial Surveillance Program (1997-2002). Diagn Microbiol Infect Dis 2004; 50(1): 59-69.

3. Wisplinghoff H, Bischoff T, Tallent SM, et al. Nosocomial bloodstream infections in US hospitals: analysis of 24,179 cases from a prospective nationwide surveillance study. Clin Infect Dis 2004, 39(3): 309-317.

4. Cosgrove SE, Sakoulas G, Perencevich EN, et al. Comparison of mortality associated with methicillinresistant and methicillin-susceptible Staphylococcus aureus bacteremia: a meta-analysis. Clin infect Dis 2003; 36(1): 53-59.

5. Department of Health. MRSA screening operational guidance. London: DoH, 2008.

DOI: 10.3399/bjgp10X514855

\section{Glycaemic control and mortality}

The last sentence of the article by Landman et al' states, "for patients with moderate glycaemic control and longstanding diabetes, it may be better to focus on other risk factors, such as smoking, high blood pressure, and lipid profile disturbances, than to aim for increasingly lower therapeutic values for $\mathrm{HbA}_{1 \mathrm{c}}$.

However, this observational cohort study showed no significant difference in baseline characteristics between the survivors and the deceased in blood pressure, lipids, and smoking characteristics.

Surely an implication of this study is that the benefits of interventions noted in other studies do not necessarily translate to improvements in the wider context of general practice.
Alan Searle,

PO Box 956, Port Orchard, WA 98366, US.

E-mail: asearle@wavecable.com

\section{REFERENCE}

1. Landman GW, van Hateren KJJ, Kleefstra N, et al. The relationship between glycaemic control and mortality in patients with type 2 diabetes in general practice (Zodiac-11). Br J Gen Pract 2010; 60(572): 172-175.

DOI: 10.3399/bjgp10X514864

\section{Authors' response}

In our article, published in the March edition of this journal, we state that 'it may be better to focus on other risk factors, such as smoking, high blood pressure, and lipid profile disturbances, than to aim for increasingly lower therapeutic values for $\mathrm{HbA}_{1 \mathrm{c} .}{ }^{.1}$ The validity of our conclusions was confirmed by a recently published large retrospective study. ${ }^{2}$ Although the design was different, it emphasised the absence of benefit of strict glycaemic control in patients with longer diabetes duration. In fact, this study even showed an increased mortality in patients with $\mathrm{HbA}_{1 c}$ under $7.5 \%$ who underwent treatment intensification with insulin.

In his comment to our article, Searle points out that there are no baseline differences in these risk factors between the survivors and the deceased in our study. ${ }^{3}$ Although this observation is correct, we respectfully disagree that it contradicts our statement. Absence of differences in baseline characteristics, for example smoking, does not mean that smoking is not an independent risk factor for mortality. To answer the question whether smoking, blood pressure, and cholesterol levels are related to mortality, Cox regression analyses, including correction for confounders, are an option in order to better interpret a (possible) effect of, in this case, $\mathrm{HbA}_{1 c}$ on mortality. For example, in the same study cohort, we studied the relationship between mortality and lipid profile in different age groups. ${ }^{4}$ In this study, higher cholesterol levels did relate to mortality.
We agree with Searle that the benefits of interventions, as studied in randomised controlled trials, do not necessarily translate to improvements in daily practice. Many trials include a selected population and are, therefore, not representative of the general population. However, our results more or less confirm the results of these trials, like the UKPDS, that we discussed in our article.

\section{Gijs Landman,}

Internal Medicine, Isala Clinics, PO BOX 10400, Zwolle, 8000 GK, the Netherlands. E-mail: g.w.d.landman@isala.nl

\section{Kornelis van Hateren,}

Diabetes Centre, Isala Clinics, the Netherlands.

\section{Nanne Kleefstra,}

Diabetes Centre, Isala Clinics, the Netherlands.

\section{Henk Bilo,}

Diabetes Centre, Isala Clinics, the Netherlands.

\section{REFERENCES}

1. Landman GW, van Hateren KJ, Kleefstra N, et al. The relationship between glycaemic control and mortality in patients with type 2 diabetes in general practice (Zodiac-11). Br J Gen Pract 2010; 60(572): 172-175.

2. Currie CJ, Peters JR, Tynan A, et al. Survival as a function of $\mathrm{HbAlc}$ in people with type 2 diabetes: a retrospective cohort study. Lancet 2010; 375(713): 481-489.

3. Searle A. Glycaemic control and mortality. Br J Gen Pract 2010; 60(576): 353.

4. Van Hateren KJ, Landman GW, Kleefstra N, et al. The lipid profile and mortality risk in elderly type 2 diabetic patients: a ten-year follow-up study (ZODIAC-13). PLoS One 2009; 4(12): e8464.

DOI: 10.3399/bjgp10X514873

\section{Dementia: the deception is broken; naked truth looks OK}

We are warmed and encouraged by the supportive responses, ${ }^{1-3}$ to our challenge to the National Dementia Strategy in its current form. ${ }^{4}$ 